\title{
ANALISIS ORNAMEN PADA BANGUNAN MASJID AL OSMANI MEDAN
}

\author{
Rendy Prayogi \\ Prodi Desain Interior Fakultas Seni dan Desain Universitas Potensi Utama \\ rendyprayogi3@gmail.com
}

\begin{abstract}
ABSTRAK
Di Kota Medan banyak terdapat bangunan bersejarah, salah satunya adalah Masjid Al Osmani, yang berfungsi sebagai tempat beribadah umat muslim sejak zaman kesultanan Melayu Deli pada abad ke-19 dan juga sebagai tempat pertemuan Sultan dengan rakyatnya. Bangunan Masjid Al Osmani memiliki arsitektur yang unik perpaduan dari budaya China, Eropa, India, Timur Tengah dan Melayu Deli. Seperti pintu masjid berornamen China, ukiran relief pada pilar bangunan bernuansa Eropa, kubah mencirikan nuansa India, serta tampilan kaligrafi mencirikan nuansa Timur Tengah dan ornamen Melayu Deli. Penelitian ini menggunakan pendekatan sejarah dan pendekatan estetika. Pendekatan sejarah akan menyangkut pembahasan tentang sejarah bangunan Masjid Al Osmani dan perkembangan fungsi bangunan sejak didirikan hingga sampai sekarang. Pendekatan estetika akan menyangkut pembahasan tentang bentuk ornamen pada bangunan Masjid Al Osmani, bagaimana bentuk ornamen dan bangunan Masjid Al Osmani tersebut terbentuk sehingga memiliki ciri khas dan dapat menarik perhatian publik?. Hasil penelitian ini memperlihatkan bahwa bangunan Masjid Al Osmani tidak seutuhnya bercirikan budaya Melayu Deli tetapi juga memiliki alkulturasi estetika bentuk dari kebudayaan China, Eropa, India dan Timur Tengah.
\end{abstract}

Kata Kunci : Masjid Al Osmani, Estetika, Histori, Ornamen.

\section{ABSTRACT}

In Medan, there are many historical buildings, one of which is the Al Osmani Mosque, which has served as a place of worship for Muslims since the era of the Malay Deli Sultanate in the 19th century and also as a meeting place for Sultan with people. The Al Osmani Mosque building has a unique architectural blend of Chinese, European, Indian, Middle Eastern and Deli Malay cultures. For example, the doors of the ornate Chinese mosque, the relief carvings on the pillars of the building have European nuances, the dome characterizes Indian nuances, and the calligraphic appearance characterizes the nuances of the Middle East and Deli Malay ornaments. This study uses a historical approach and an aesthetic approach. The historical approach will involve a discussion of the history of the building of the Al Osmani Mosque and the development of the building's function since its establishment until now. The aesthetic approach will involve a discussion of the shape of the ornament in the Al Osmani Mosque building, how is the shape of the ornament and the Al Osmani Mosque building formed so that it has distinctive features and can attract public attention? The results of this study indicate that the building of the Al Osmani Mosque is not completely characterized by Deli Malay culture but also has aesthetic acculturation of forms from Chinese, European, Indian and Middle Eastern cultures.

Keywords : Al Osmani Mosque, Aesthetic, History, Ornaments. 


\section{PENDAHULUAN}

Di Kota Medan banyak terdapat bangunan bersejarah, salah satunya adalah Masjid Al Osmani. Masjid Al Osmani berfungsi sebagai tempat beribadah umat muslim sejak zaman kesultanan Melayu Deli pada abad ke-19 dan juga sebagai tempat pertemuan Sultan dengan rakyatnya. Pertama kali dibangun pada tahun 1854 dengan bahan kayu pilihan yang didatangkan dari Penang. Pada masa Kesultanan Melayu Deli ke-VII yaitu Sultan Osman Perkasa Alam, masjid ini dibangun tepat di depan Istana Kesultanan Deli di Labuhan Deli. Kemudian pada tahun 1870 - 1872 masjid yang terbuat dari bahan kayu itu dibangun permanen oleh putranya yang bernama Sultan Mahmud Perkasa Alam (Sultan Deli ke-VIII). Bangunan Masjid Al Osmani di desain oleh arsitek asal Jerman yang bernama G.D. Langereis dengan material yang dikirim dari Eropa dan Persia. Bangunan Masjid Al Osmani ini berada di Jalan Yos Sudarso KM 17,5, Kelurahan Pekan Labuhan, Kecamatan Medan Labuhan, Kota Medan, Sumatera Utara.

Masjid Al Osmani merupakan Masjid tertua dan salah satu tempat tujuan wisata di kota Medan. Bangunan Masjid Al Osmani ini didominasi dengan warna kuning keemasan dan dipadukan dengan warna hijau. Bangunan Masjid Al Osmani berukuran 26 x 26 meter yang berdiri di atas tanah seluas 2 hektar. Masjid ini memiliki arsitektur yang unik dengan perpaduan dari China, Eropa India, Timur Tengah dan Melayu Deli.

Suatu karya seni dan desain tidak dapat terpisahkan dari kehidupan manusia. Adanya hal ini mengemukakan dalam pemikiran logis dapat di gambarkan bahwa seni dan desain sudah ada sejak manusia berada di muka bumi dan terus berkembang sampai saat ini. Archer (1965) menjelaskan bahwa di dalam mendesain itu memerlukan analisis, kreatif dan pelaksanaan. Salah satu dari keistimewaan proses perancangan adalah fase analisis yang memerlukan observasi obyektif dan pemikiran induktif sedangkan fase kreatif memerlukan keterlibatan pendapat subyektif dan pemikiran deduktif. Setelah keputusan dibuat, proses perancangan dilanjutkan dengan pelaksanaan pengerjaan gambar teknik, jadwal dan lain-lain yang juga dalam keadaan obyektif dan deskriptif.

Dari berbagai pendapat para ahli dan penjelasannya, pengertian desain dapat pula diartikan Desain ialah semua hal yang berhubungan pembuatan konsep, analisis data, project planning, drawing/rendering, cost calculation, prototying, frame testing dan test riding. Pengertian mengenai desain ini dijabarkan lebih rinci oleh Sachari, Agus (2005: 78) proses perancangan atau perencanaan dari suatu objek yang bertujuan membuat objek yang dibuat memiliki fungsi, memiliki nilai keindahan dan bermanfaat bagi manusia.

\section{I.1. MASJID}

Nabi Muhammad SAW bersabda bahwa Masjid adalah tempat dimana orang muslim bersembahyang "Masjid itulah tempat engkau bersembahyang". Sebanyak 20 kali kata Masjid di sebutkan di dalam Al- Qur'an, yang berasal dari kata sajada / sujud, tunduk penuh hormat dan takzim, patuh dan taat (Sumalyo, 2006: 1).

Di Negara Indonesia banyak di temukan bangunan Masjid, beberapa diantaranya memiliki nilai sejarah dari perkembangan kota tersebut sebelum agama Islam berkembang di Indonesia, sehingga bangunan masjid-masjid itupun berusia ratusan tahun. Di lihat dari sejarahnya, bentuk-bentuk bangunan Masjid di Indonesia juga beraneka ragam, ada yang mencirikan budaya lokal setempat dan ada pula pengaruh dari negara asing. Yang sangat jelas, bentuk bangunan Masjid tidak bertolak belakang dari fungsi dan tujuannya sebagai tempat umat muslim bersembahyang (I G.N. Anom, 1992:1).

\section{I.2. ORNAMEN}

Ornamen ialah ekspresif estetik yang ditampilkan dalam berbagai karya buatan manusia. Selain itu, ornamen juga merupakan produk lokal yang lahir dari kebudayaan 
daerah dan digunakan oleh para leluhur untuk kehidupan bersama. Ornamen juga dapat diartikan sesuatu yang sengaja dirancang untuk menambah kesan keindahan suatu benda. Ornamen dalam bahasa lokal dapat disebut juga sebagai ragam hias yang artinya karya seni yang dibuat sebagai hiasan demi keindahan suatu produk. Selain mengandung unsur menghias, faktor keindahan sengaja di tampilkan sebagai tujuannya. Disebut pula bahwasanya ornamen ialah sebuah bentuk estetik yang memiliki fungsi sebagai menambah kesan indah pada benda kerajinan sehingga terwujud bentuk yang menarik dan indah (Ekoprawoto, 1998: 36).

Dalam buku "Ornamen Nusantara" karyanya Sunaryo (2009:3) mendefinisikan bahwa ornamen ialah penerapan hiasan pada suatu karya seni. Ornamen dalam bentuk hiasan tersebutpun memiliki fungsi utama yaitu sebagai memperindah produk atau karya seni. Produk tadi sebelumnya sudah sangat indah, tetapi setelah di tambahkan ornamen pada produk tersebut dapat di harapkan menjadi semakin estetik.

Ornamen yang terdapat pada bangunan Masjid biasanya di ukir ataupun di tempel menggunakan material yang ditujukan sebagai hiasan. Ornamen itupun dapat diwujudkan di dinding ataupun menjadi bagian dari struktur bentuk bangunan Masjid, seperti ornamen yang diwujudkan pada bagian jendela, pintu, ventilasi udara dan plafon. Ornamen tidak semuanya berupa tumbuhan ataupun binatang, tetapi adapula ornamen yang berupa bentuk garis lurus / miring ataupun patah-patah, lingkaran, persegi, spiral yang kemudian dapat dikembangkan menjadi bermacam jenis ornamen yang beraneka ragam. Ornamen juga memiliki unsurunsur dasar desain seperti titik, garis, bidang, ruang, warna, tekstur, berirama, keseimbangan, kesatuan serta rotasi.

Metode yang digunakan dalam analisis ini adalah metode kualitatif yang disajikan dengan cara di uraikan dan bersifat terkesan, berpendapat (penafsiran) yang di dapatkan dari hasil observasi. (Sulistyo-Basuki, 2006:78) menjelaskan tujuan dari penelitian kualitatif adalah memperoleh gambaran mengenai suatu hal atau objek menurut pandangan sih peneliti. Penelitian kualitatif inipun berhubungan dengan pendapat / ide, persepsi, ataupun kepercayaan orang yang meneliti; semuanya itu tidak dapat diukur menggunakan angka.

Pada bangunan Masjid biasanya terdapat beberapa jenis motif ornamen, diantaranya sebagai berikut :

a. Motif Geometris (Arabesque)

Biasanya di dalam arsitektur Islam terdapat dekorasi atau simbol-simbol (gemetris pattern and lotus) biasa disebut motif geometris (Arabesque) dengan bentuk yang mengandung unsur garis, lingkaran, bidang, segi tiga, segi lima dan sebagainya (Pancawaty dan Faqih, 2012: 2).

b. Motif Tumbuhan

Umumnya motif hias daun berbentuk stilisasi sehelai daun yang diulang-ulang tersusun berderet, tetapi motif daun juga merupakan gubahan dedaunan yang merupakan bagian motif tumbuh-tumbuhan. Seperti sejenis tunas atau batang tanaman menjalar yang masih muda dan melengkung-lengkung bentuknya. Sementara sulur dipakai untuk menanamkan motif hias tumbuh-tumbuhan yang digubah dengan bentuk dasar lengkung pilin tegar dan juga bagian batang yang menjalar menyerupai spiral.

c. Motif Binatang

Motif ornamen binatang pada bangunan Masjid biasanya sudah memasuki hasil ubahan, jarang sekali ditemui berupa binatang secara natural. Jenis motif yang menggunakan wujud binatang seluruhnya atau bagian tertentu sebagai gagasan utama ragam hias. Bentuk motif binatang bisa saja digubah dengan cara stilasi, distori maupun secara natural, baik perwujudan seluruh tubuh binatang maupun bagian tubuh tertentu. 
Ada beberapa proses tahapan dalam analisis data :

1. Analisa data dengan cara mengumpulkan data berupa tulisan, gambar / foto, baik yang didapatkan melalui studi literatur, observasi langsung objek penelitian maupun wawancara kepada narasumber.

2. Melakukan pemilahan data atau mengelompokkan data-data yang telah teridentifikasi sesuai dengan jenisnya.

3. Penyeleksian data, yaitu memisahkan antara data yang tidak relevan terhadap pokok bahasan dalam penelitian ini.

4. Analisis data sesuai dengan pendekatan yang digunakan pada penelitian ini yaitu pendekatan sejarah seni dan desain serta pendekatan estetika.

\section{STUDI LITERATUR}

Pada suatu bangunan, ornamen memiliki fungsi dasar sebagai elemen yang sengaja diwujudkan untuk memperindah ruang kosong pada sebuah produk, kemudian menjadi sebuah karya seni yang indah dan menarik. Seiring dengan perkembangannya. Ornamen tidak hanya dijadikan sebagai memperindah saja, tetapi juga memiliki fungsi lain seperti menjadi wadah sebagai sarana komunikasi atau sarana informasi bagi masyarakat budaya lokal. Letak ornamen pada bangunan Masjid dapat diklasifikasikan menjadi :

1. Ornamen dibagian kubah masjid,

2. Ornamen dibagian dinding, jendela dan pintu masjid,

3. Ornamen dibagian konstruksi bangunan masjid,

4. Ornamen dibagian mihrab masjid,

5. Ornamen dibagian langit-langit (Plafond) masjid.

Dalam menganalisis berbagai jenis ornamen pada bangunan Masjid Al Osmani ini, terdapat beberapa karya tulisan yang dapat digunakan sebagai referensi. Pertama, tulisan Ayu Kartini (2014) dalam penelitiannya menjelaskan tentang motif, warna, bentuk dan makna ornamen melayu yang ada dikota Medan. Kedua, tulisan Nursyazwani (2015) menjelaskan tentang jenis-jenis dan bentuk ornamen melayu. Ketiga, penelitian dari M. Ilham (2017) menjelaskan letak ornamen yang ada di Masjid Raya Al Osmani, jenis kaligrafi yang terdapat pada bagian Mihrab Masjid yaitu kaligrafi jenis Khat Kufi dan Khat Sulus.

\section{III.PEMBAHASAN}

Masjid Al Osmani Medan memiliki konsep arsitektur yang unik, megah dan memiliki karakter unsur tradisional dari budaya setempat yaitu budaya Melayu Deli. Baik bentuk bangunan maupun ornamen Masjid Al Osmani ini menampilkan kombinasi arsitektur dari empat Negara, antara lain China, Eropa, Timur Tengah, dan India. Alkulturasi arsitektur empat Negara itu misalnya pada bagian pintu Masjid dengan ukiran relief China, ukiran relief pada pilar bangunan bernuansa Eropa, kubah yang besar dan berwarna hitam bernuansa India, dan tampilan kaligrafi mencirikan nuansa Timur Tengah serta ornamen Melayu Deli. Bangunan Masjid Al Osmani ini juga didominasi dengan warna kuning keemasan yang identik dengan warna khas Melayu Deli, warna tersebut diartikan atau menunjukkan kemegahan dan kemuliaan. Kemudian dipadukan dengan warna hijau yang filosofinya menunjukkan keislaman. 


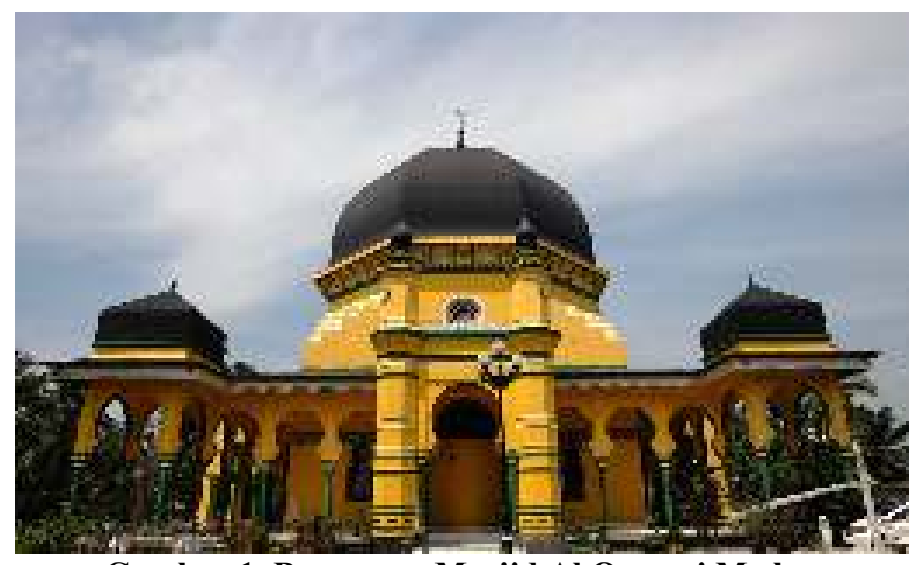

Gambar 1. Bangunan Masjid Al Osmani Medan

Masjid Al Osmani merupakan tempat beribadah umat muslim sejak zaman kesultanan Melayu Deli pada abad ke-19 dan juga sebagai tempat pertemuan Sultan dengan rakyatnya untuk bermusyawarah. Disekitaran masjid juga terdapat makam para sultan Melayu Deli, yakni makam Sultan Deli ke-IV bernama Tuanku Panglima Pasutan, makam Sultan Deli ke-V bernama Tuanku Panglima Gandar Wahid, makam Sultan Deli ke-VI Sultan Amaluddin Perkasa Alam, makam Sultan Deli ke VII bernama Sultan Osman Perkasa Alam, dan makam Sultan Deli ke-VIII bernama Sulthan Mahmud Perkasa Alam.

\section{III.1. KUBAH MASJID}

Bangunan Masjid Al Osmani memiliki kubah tunggal dengan bentuk persegi delapan (octagonal) dengan berat 2,5 Ton. Kubah pada bangunan Masjid Al Osmani ini berbentuk kubah bawang (Onion Dome) jenis kubah seperti ini banyak dijumpai pada zaman Rennainsance (sekitar tahun 1300 - $1600 \mathrm{M}$ ) dan banyak digunakan untuk bangunan gereja di Eropa seperti kubah gereja Basilika S. Peter yang menggunakan kerangka kubah dengan bentuk dasar segi delapan dan sedikit menjorok keluar dibagian tengah kubah,

Fungsi dari kubah Masjid Al Osmani sebagai komponen desain untuk memperindah bangunan masjid. Selain itu fungsi kubah pada masjid untuk melindungi perlengkapan masjid yang ada didalam bangunan. Pengaruh India terdapat pada bagian kubah Masjid Al Osmani, dengan kubah masjid yang berwarna hitam (Ahmad Faruni : 2019). Pada kubah Masjid Al Osmani terdapat ornamen yang diambil dari bentuk geometris yaitu ornamen bunga matahari, yang terdapat dibawah kubah bagian luar.

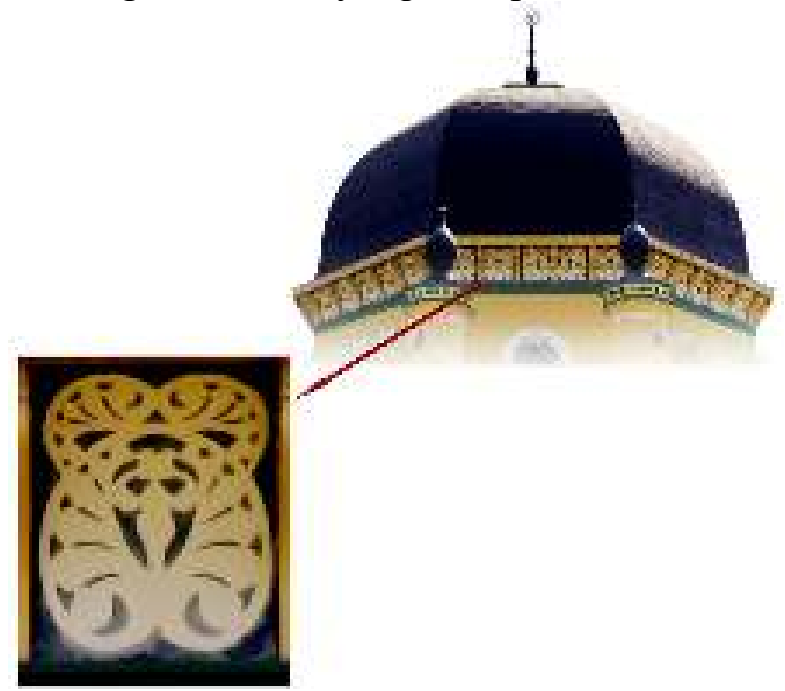

Gambar 2. Kubah Masjid Al Osmani Medan 


\section{III.2. Dinding, Jendela dan Pintu Masjid Al Osmani}

Pada dinding Masjid Al Osmani juga terdapat ornamen yang dibuat dari cat minyak dengan motif floralist yang distilir dan naturalis. Pada bagian pintu Masjid Al Osmani ini ialah pengaruh dari China dengan ukiran yang disebut ornamen bunga cina atau bunga susun kelapa.
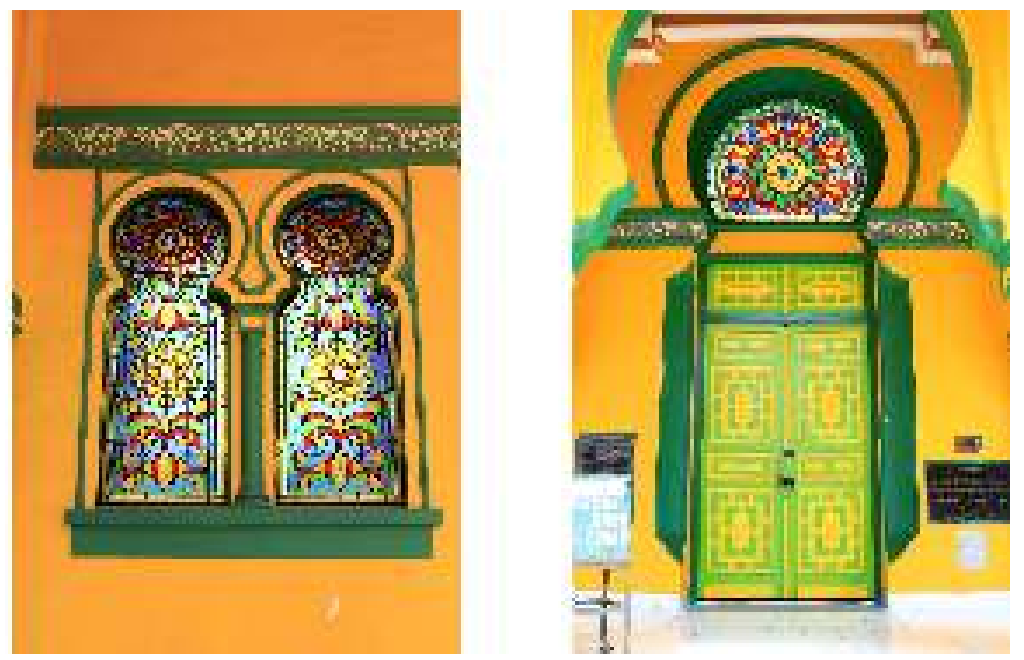

Gambar 3. Dinding, Jendela dan Pintu Masjid Al Osmani Medan

Terdapatnya pintu yang memiliki ornamen bunga cina ini dikarenakan sumbangan dari salah satu tokoh orang China yang sangat dipandang di Kota Medan yang bernama Tjong A Fie (Ahmad Faruni : 2019). Sedangkan pada bagian jendela Masjid Al Osmani terdapat ornamen dengan teknik lukis pada bagian kaca jendela.

Tabel 1. Ornamen Pada Dinding, Jendela dan Pintu Masjid Al Osmani

\begin{tabular}{|c|c|c|c|c|}
\hline $\begin{array}{l}\text { Jenis Motif } \\
\text { Ornamen }\end{array}$ & $\begin{array}{c}\text { Bentuk Motif Ornamen } \\
\text { Pada Bangunan }\end{array}$ & $\begin{array}{l}\text { Bentuk Drawing } \\
\text { Motif Ornamen }\end{array}$ & $\begin{array}{c}\text { Nama Motif } \\
\text { Ornamen }\end{array}$ & $\begin{array}{c}\text { Warna } \\
\text { Motif } \\
\text { Ornamen }\end{array}$ \\
\hline Binatang & & & Ekor Merak & Hijau \\
\hline Tumbuhan & & $\begin{array}{l}60.35 \\
6003 \\
60.35 \\
6033\end{array}$ & $\begin{array}{c}\text { Bunga Cina / } \\
\text { Bunga Susun } \\
\text { Kelapa }\end{array}$ & $\begin{array}{l}\text { Hijau, } \\
\text { Kuning }\end{array}$ \\
\hline Tumbuhan & & & Bunga Roda & $\begin{array}{c}\text { Merah, } \\
\text { Kuning, } \\
\text { Hijau, dan } \\
\text { Biru }\end{array}$ \\
\hline Tumbuhan & & & $\begin{array}{l}\text { Bunga } \\
\text { Melati }\end{array}$ & $\begin{array}{c}\text { Hijau, Biru } \\
\text { Merah, dan } \\
\text { Kuning }\end{array}$ \\
\hline
\end{tabular}




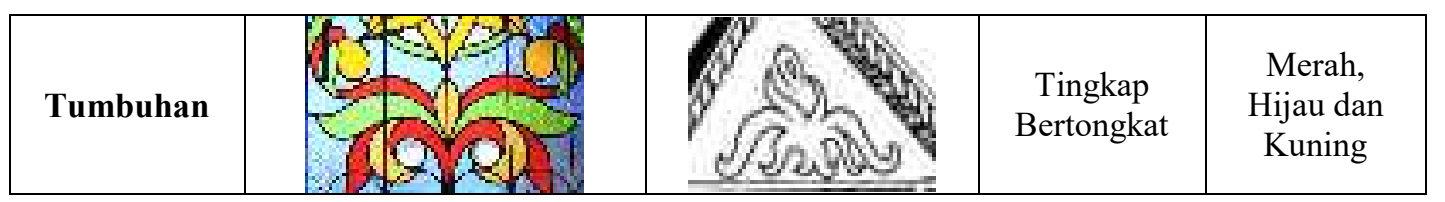

\section{III.3. Konstruksi Bangunan}

Ukiran / relief bangunan Masjid Al Osmani ini adalah pengaruh dari Eropa terutama pada bagian lengkungan pilar-pilar Masjid yang disebut dengan lengkungan tapal kuda, mirip dengan Masjid Cordoba yang ada di Spanyol.

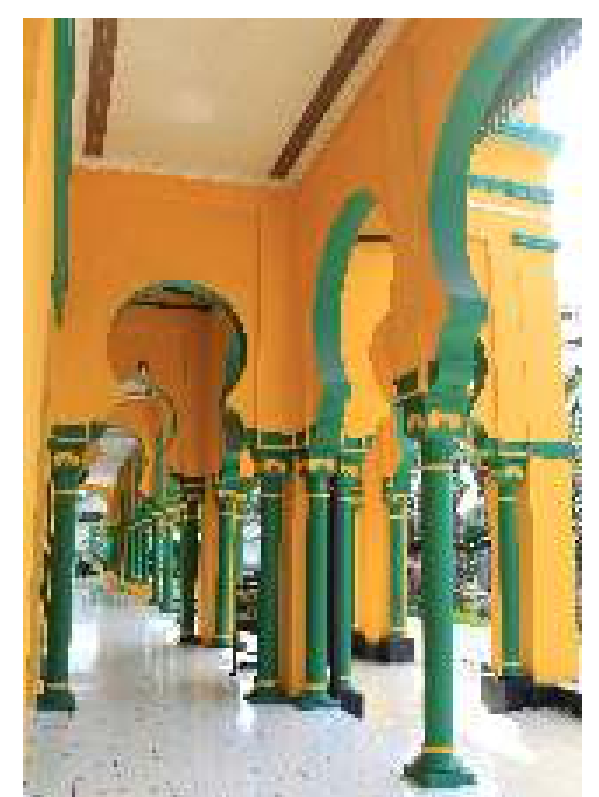

\section{Gambar 4. Konstruksi Masjid Al Osmani Medan}

\section{III.4. Mihrab Masjid Al Osmani}

Keberadaaan lengkungan (arcade) pada atap dan pintu Mihrab Masjid Al Osmani ini menganut arsitektur Islam / lengkungan khas dari Timur Tengah, dengan terdapat kaligrafi surah Al-Baqarah ayat 144, kalimat Allah dan Muhammad yang hanya terpusat pada bagian kanan dan kiri Mihrab Masjid saja.

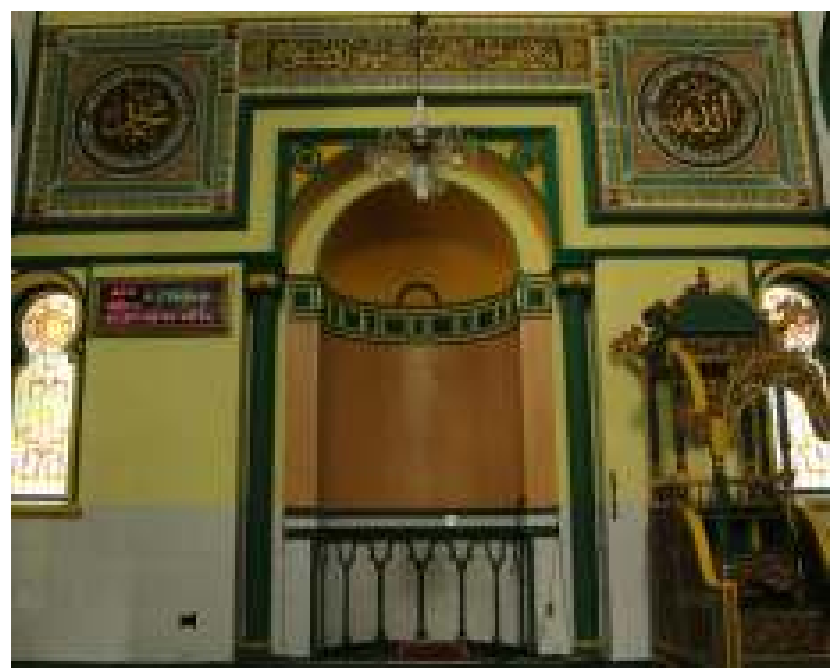

Gambar 5. Mihrab Masjid Al Osmani Medan 
Selain Ayat Suci Al Quran pada bagian Mihrab Masjid Al Osmani juga terdapat beberapa ukiran ornamen Melayu Deli yang dibuat menggunakan cat minyak dengan motif floralist yang distilir dan naturalis.

Tabel 2. Ornamen Pada Mihrab Masjid Al Osmani

\begin{tabular}{|c|c|c|c|c|}
\hline $\begin{array}{l}\text { Jenis Motif } \\
\text { Ornamen }\end{array}$ & $\begin{array}{c}\text { Bentuk Motif Ornamen } \\
\text { Pada Bangunan }\end{array}$ & $\begin{array}{l}\text { Bentuk Drawing } \\
\text { Motif Ornamen }\end{array}$ & $\begin{array}{l}\text { Nama Motif } \\
\text { Ornamen }\end{array}$ & $\begin{array}{c}\text { Warna } \\
\text { Motif } \\
\text { Ornamen } \\
\end{array}$ \\
\hline Agama & s. & 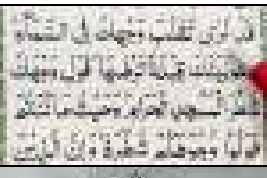 & $\begin{array}{c}\text { Surah Al- } \\
\text { Baqarah } \\
\text { Ayat } 144\end{array}$ & $\begin{array}{l}\text { Kuning dan } \\
\text { Coklat }\end{array}$ \\
\hline Agama & & & $\begin{array}{l}\text { Kaligrafi } \\
\text { Allah }\end{array}$ & $\begin{array}{l}\text { Hijau, } \\
\text { Kuning } \\
\text { dan } \\
\text { Coklat }\end{array}$ \\
\hline Agama & & & $\begin{array}{c}\text { Kaligrafi } \\
\text { Muhammad }\end{array}$ & $\begin{array}{c}\text { Hijau, } \\
\text { Kuning dan } \\
\text { Coklat }\end{array}$ \\
\hline Tumbuhan & & & $\begin{array}{l}\text { Bunga } \\
\text { Cengkeh }\end{array}$ & $\begin{array}{l}\text { Coklat, } \\
\text { Hijau, } \\
\text { Merah dan } \\
\text { Kuning }\end{array}$ \\
\hline Tumbuhan & & & $\begin{array}{l}\text { Bunga } \\
\text { Cengkeh }\end{array}$ & $\begin{array}{l}\text { Coklat, Hijau, } \\
\text { Biru, Merah, } \\
\text { dan Kuning, }\end{array}$ \\
\hline Tumbuhan & & & $\begin{array}{l}\text { Kelopak } \\
\text { Empat }\end{array}$ & $\begin{array}{l}\text { Hijau, Biru, } \\
\text { Merah } \\
\text { Muda, dan } \\
\text { Kuning }\end{array}$ \\
\hline Tumbuhan & & & $\begin{array}{l}\text { Kuntum } \\
\text { Setaman }\end{array}$ & $\begin{array}{c}\text { Hijau, } \\
\text { Merah, Biru, } \\
\text { Merah Muda, } \\
\text { dan Kuning }\end{array}$ \\
\hline
\end{tabular}




\section{III.5. Langit-langit (Plafon) Masjid Al Osmani}

Bentuk kubah tidak hanya memiliki permukaan bagian luar, tetapi juga memiliki bagian ruang dalam. Pada langit-langit kubah Masjid Al Osmani dengan ukuran 8 x 8 meter ini juga memiliki ornamen-ornamen yang diambil dari bentuk floralis / tumbuhan dan binatang.

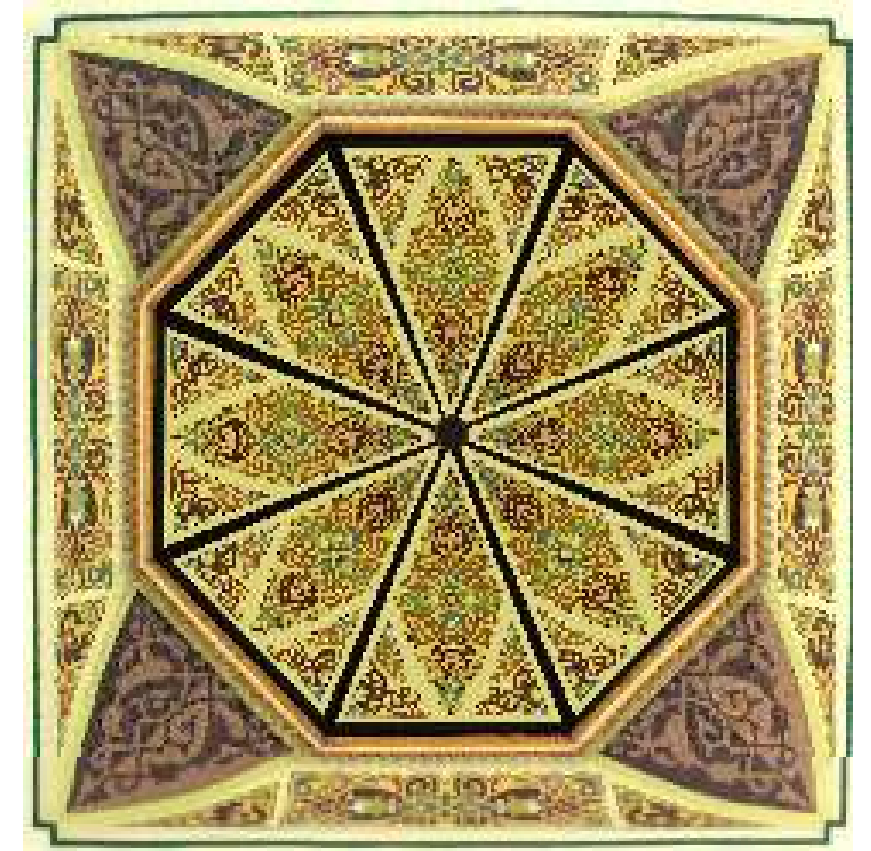

Gambar 6. Langit-langit (Plafon) Masjid Al Osmani Medan

Struktur kubah masjid Al Osmani Medan dibuat menggunakan rangka tembaga yang bertumpu pada setiap sudut dinding yang berbentuk persegi delapan (mengikuti bentuk kubah), sisi dalam kubah dibuat menggunakan kayu damar yang dianggap oleh manajemen masjid dapat mengatasi serangan serangga rayap sekaligus berfungsi sebagai langit-langit (plafon) pada kubah.

Tabel 3. Ornamen Pada Langit-langit (Plafon) Masjid Al Osmani

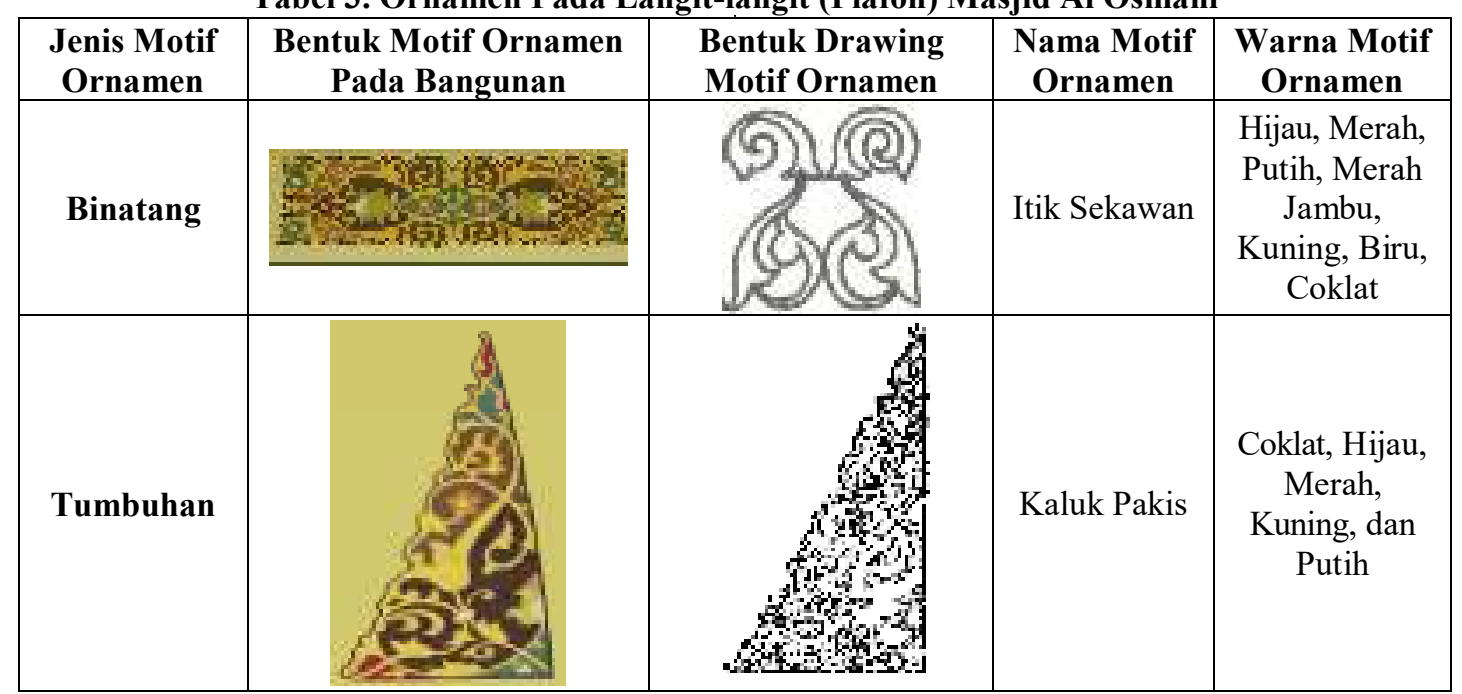




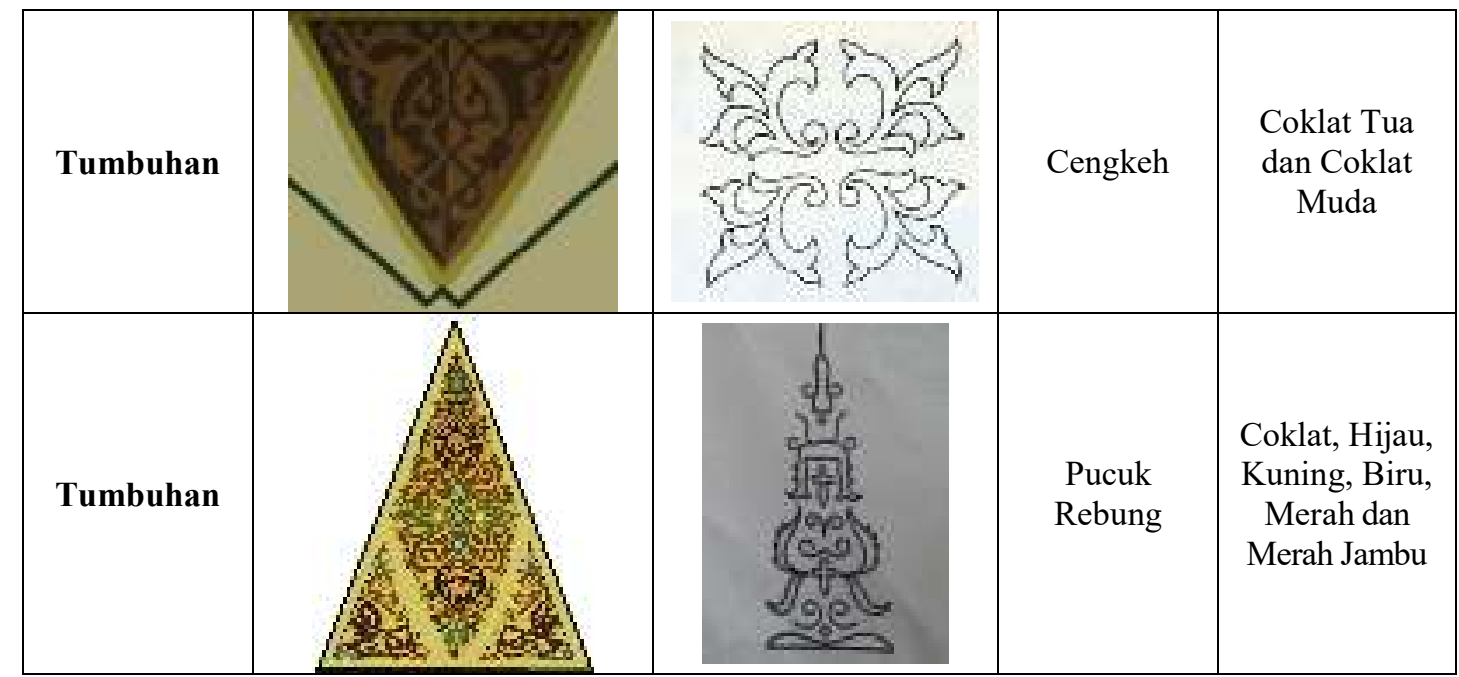

\section{KESIMPULAN}

Berbagai jenis dan bentuk ornamen Melayu Deli banyak ditemukan pada bangunan Masjid Al Osmani Medan. Bentuk ornamen yang terdapat pada bangunan Masjid Al Osmani Medan ialah bentuk dari tumbuhan, bentuk dari binatang, bentuk geometris dan kaligrafi. Bentuk-bentuk ornamen tersebut dapat ditemui hampir setiap sudut bangunan Masjid sehingga menambah keindahan bangunan Masjid Al Osmani Medan. Selain ornamen, bangunan Masjid Al Osmani diisi dengan mimbar untuk Tabligh dan dakwah Khutbah, lampu Kristal dan bentuk relief pada pilar bangunan yang bergaya Eropa.

\section{DAFTAR PUSTAKA}

[1] Anom, I G. N 1998/1999, Masjid Kuno Di Indonesia. Direktorat Perlindungan dan Pembinaan Peninggalan Sejarah dan Purbakala Departemen Pendidikan dan Kebudayaan : Jakarta.

[2] Archer, L. B. (1964). Systematic method for designers. Design, 56-59.

[3] Basuki, S. (2008). Metode penelitian, Jakarta: Penaku. Departemen Agama.

[4] Prawoto, A. E. (1998). Makna Simbolik Ornamen Pada Arsitektur Rumah Melayu. Medan.

[5] Kartini, A. (2014). Analisis Penerapan Ornamen Bernuansa Melayu Ditinjau Dari Bentuk dan Warna di Kota Medan, Medan.

[6] Ilham, M. (2017). Analisis Kaligrafi Pada Masjid Raya Al-Osmani Medan Labuhan Kota Medan (Kajian Semiotika), Medan.

[7] Nursyazwani, M. Y. (2015). Analisis Semiotika Pada Ornamen Masjid Azizi Langkat, Medan.

[8] Sachari, A. (2005). Pengantar Metode Penelitian Budaya Rupa (Desain, Arsitektur, Seni Rupa, dan Kriya), Jakarta : Erlangga.

[9] Sumalyo, Y. (2006). Arsitektur Mesjid dan Monumen Sejarah Muslim. Yogyakarta: Gadjah Mada University Press. 